\title{
SARS-CoV-2: REALITY AND CHALLENGES IN TREATMENT AND VACCINE DEVELOPMENT, WHERE DO WE STAND?
}

\author{
NEEVAARTHANA SUBRAMANIAM AND NOR FAZILA CHE MAT** \\ School of Health Sciences, Health Campus, Universiti Sains Malaysia, 16150 Kubang Kerian, Kelantan, Malaysia. \\ *Corresponding author: fazilacm@usm.my \\ Submitted final draft: 28 December 2020 Accepted: 7 January $2021 \quad$ http://doi.org/10.46754/jssm.2021.10.020
}

\begin{abstract}
The newly emerged SARS-CoV-2 has been a threat to the health of humans throughout the world. It causes mild to severe respiratory illness, mainly characterized by fever, cough, loss of taste and smell sensation and other respiratory symptoms. As this disease has been causing unsolicited deaths, antiviral treatment and vaccines are being continuously developed and clinically tested for their effectiveness against SARS-CoV-2. A wide variety of treatment options and vaccine candidates were observed to be tested in different stages of development in different durations. Although progress has been recorded from time to time, a proper treatment and vaccine acceptable for universal use has yet to be developed due to certain constraints. This review unfolds the prevailing treatment and vaccine development along with the challenges faced in developing them in a short period of time.
\end{abstract}

Keywords: SARS-CoV-2, treatment, vaccine, potential, challenges.

\section{Introduction}

The coronavirus disease 19, COVID-19 or severe acute respiratory syndrome coronavirus 2 (SARS-CoV-2), is a rapidly emerging infectious viral disease and considered a health emergency worldwide. The outbreak first emerged in Wuhan, China in 2019, and was suspected to have developed from bat viruses, with the most common clinical features being fever and other respiratory illnesses and most severely death (Mackenzie \& Smith, 2020). SARS-CoV-2 rapidly spread across geographical ranges, by human to human transmission through respiratory droplets or fluids from coughing and sneezing of infected humans (Riou \& Althaus, 2020, Unhale et al., 2020). Due to effective mutation of the virus itself, the virus is known to be extremely contagious and can infect several people at a time (Unhale et al., 2020). At the time of writing, there are more than five million SARS-CoV-2 cases and more than 300,000 deaths worldwide (World Health Organization, 2020a). These large numbers had forced many countries to implement complete and partial lockdowns, triggering economic recessions and interrupting daily work-related human activities.
To fight SARS-CoV-2, efforts to introduce effective preventive and therapeutic approaches have been taking place. Antiviral treatments inhibit the reproduction of viruses. However, antiviral treatment needs to be constantly upgraded, as viruses mutates and develop resistance towards existing drug (The National Academies, 2020). In contrast, vaccines function by imitating an infection in the body to develop immunity that produce antibodies and T-lymphocytes that will help prevent further spread of the infection (Centres for Disease Control and Prevention, 2018). In the current health scenario, treatment and vaccine development are needed immediately for recovery and prevention, respectively. In this case, several inhibitors have been highlighted to mainly inhibit replication and transcription of the SARS-CoV-2 virus through drug repurposing and usage of potential drugs (Bhardwaj et al., 2020a, Senger et al., 2020). However, all strategies are still at basic levels of development, making it time-consuming and costly. As of $28^{\text {th }}$ May 2020, there are more than 2,751 globally active on-going projects on combatting SARSCoV-2 in 132 countries, estimated to involve 
about 277 billion dollars (World Bank, 2020). While treatments and vaccines are under progressive development, aggressive isolation is the best temporary prevention measure that can be taken to reduce transmission of SARSCoV-2.

This review comprises the recent advances in therapeutic and prevention efforts by researchers worldwide. This review will be valuable to provide sufficient knowledge and insights on the molecular information of SARS$\mathrm{CoV}-2$, current status and challenges faced in treatment and vaccine development against the novel coronavirus.

\section{Development of Treatments Targeting Structural and Non-structural Proteins of SARS-CoV-2}

Drugs that are used in the treatment of SARSCoV-2 infected patients normally work by targeting protein structures of SARS-CoV-2. SARS-CoV-2 is known to exist as a single stranded RNA, belonging to the betaCoVs category, round or elliptic, with a diameter of 60 - $140 \mathrm{~nm}$ and often seen in a pleomorphic form (Cascella et al., 2020). The genetic fragments of this virus express structural and non-structural proteins. Major structural protein targets include the spike (S) protein, membrane (M) protein, envelope $(\mathrm{E})$ protein, and the nucleocapsid $(\mathrm{N})$ protein along with other structural proteins such as hemagglutinin esterase (HE) glycoprotein (Hilgenfeld, 2014). Non-structural proteins, on the other hand, arise from the processing of polyproteins (PP1a and PP1ab) (McBride et al., 2014). The $\mathrm{S}$ protein is a structural protein that protrudes from the viral surface of the coronavirus, making the virus appear crownlike (Walls et al., 2020, Coutard et al., 2020). $\mathrm{S}$ protein immensely important in aiding the process of viral entry through the angiosteninconverting enzyme 2 (ACE2) host receptor. The development of many antiviral drugs is targeting this mechanism due to its promise as a drug target point (Liu et al., 2020). In regard to $\mathrm{S}$ protein, Nafamostat, also used as a treatment for pancreatitis, is currently under clinical investigation to function as a therapeutic agent against SARS-CoV-2 (Wondmkun et al., 2020).

The N protein is made up of three intrinsically disordered regions (IDR), consisting of the arm, central linker and tail domains (Chang et al., 2016). $\mathrm{N}$ protein is mainly responsible for preventing the proliferation of viral offspring, making it another highly regarded drug target after the S protein (Satarker et al., 2020). The M protein had been indicated to be present in two forms, one short and another long, where the long form is usually known to build $\mathrm{S}$ proteins (Neuman et al., 2011). The M protein together with the $\mathrm{N}$ protein is usually responsible for the maintenance of the viral envelope and also functions in the formation and release of viruslike particles (Schoeman et al., 2019). Among all other proteins present, this protein is basically present in the most generous amount (EA et al., 2019). Next, the E protein is comparatively the smallest protein, consisting of a hydrophobic domain and a charged cytoplasmic tail (Kuo et al., 2007, Venkatagopalan et al., 2015). The E protein focuses on viral morphogenesis, particularly during viral assembly and budding formation, as well as is responsible for determining the virulence factor of a virus (Venkatagopalan et al., 2015). Several antivirals, antibacterial, antitumor and anti-inflammatory drugs have been tested against SARS-CoV-2 as they are known to have a relatively good level of compatibility to the protein targets of N, M and $\mathrm{E}$, potentially known to enable viral replication (Wondmkun et al., 2020). Finally, although not heavily studied, hemagglutinin esterase (HE) glycoprotein has the ability to act as lectins or also known as receptor destroying enzymes (Zeng et al., 2008). However, the effectiveness of targeting this protein is disputed as it has several issues related to toxicity and specificity when used as drug targets (Frick et al., 2006).

Polyproteins, on the other hand, appear as non-structural proteins that are usually produced by open reading frame (ORF) $1 \beta$ (Gildenhuys, 2020). Each polyprotein plays different roles and functions through separate actions of the binding process (Yoshimoto et 
al., 2020). Among all existing polyproteins, the four most considered targets for drug discovery are the 3-chymotrypsin-like protease (3CLpro), RNA-dependent RNA polymerase (RdRp), papain-like protease (PLpro), and helicase, due to the presence of a clear enzyme active site and important biological functions (Subissi et al., 2014). At this point, several repurposed drugs had been reported to be under preclinical and clinical studies, targeting polyproteins, to test their effectiveness against SARS-CoV-2 (Wondmkun et al., 2020). These proteins have also been reported to be the most focussed upon, currently and in future, for the development of therapeutics against SARS-CoV-2 (Wondmkun et al., 2020). Collectively, all protein targets discussed have great potential to aid in the process of drug development against SARSCoV-2, however, more trials are still required to identify the best outcome, either from a repurposed or a newly developed drug.

Potential Antiviral Treatment for SARSCoV-2

\section{Potential Drugs: Classification and Mechanisms of Action}

Many individuals infected with SARS-CoV-2 have died due to the absence of antiviral drugs. Hence, a globally acceptable drug must be identified while waiting for a permanent preventive solution in the form of vaccine. Solidarity clinical trials (testing of drugs on an international scale) are reported to have been initiated by the World Health Organization (WHO) to test the effectiveness of potential drugs among patients from multiple countries (World Health Organization, 2020b). The drugs recommended by WHO had also been included as a part of the European Discovery Project in their initial clinical trials (Eynde, 2020b). The attempt of a single randomized trials had been done on drugs such as Remdesivir, Lopinavir/ Ritonavir, Lopinavir/Ritonavir with Interferon beta-1 $\beta$ (IFN- $\beta$ ) and Hydroxychloroquine/ Chloroquine (HCQ/CQ) as treatment options (World Health Organization, 2020b).

Malaysia had been reported to be one of the countries to be included in this clinical trial (New Straits Times, 2020). The trial in Malaysia will be aided by the Ministry of Health $(\mathrm{MOH})$, Institute for Clinical Research (ICR) and Clinical Research Malaysia (CRM) (World Health Organization, 2020c). These drugs can be divided into several inhibitor categories based on their mechanism of actions. Remdesivir is observed to target viral replication while Lopinavir/Ritonavir are seen to target viral proteases. $\mathrm{HCQ} / \mathrm{CQ}$, on the other hand, work by targeting the viral entry of SARS-CoV-2 virus for inhibition. These drugs have distinctive functions as inhibitors, where the main goal is to eliminate the virus from the human body at cellular level. Examples of other drug options that are FDA approved are included for further information. The general classification of the SARS-CoV-2 drugs can be seen in Table 1. 


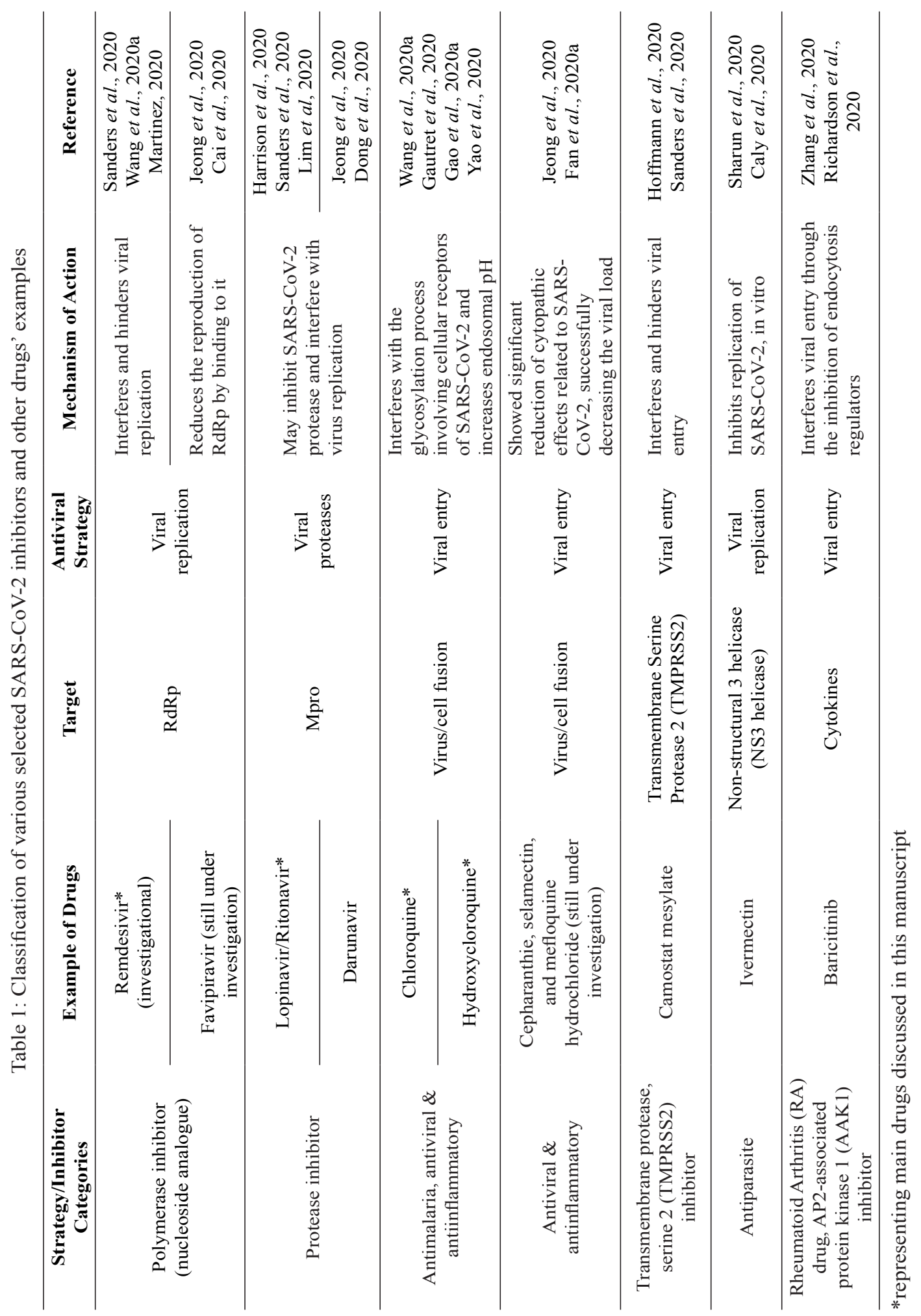


These drugs act as inhibitors at different stages of viral penetration. Focussing on the main drugs discussed, $\mathrm{HCQ} / \mathrm{CQ}$ can act in many modes of action to treat SARS-CoV-2, at an intracellular level. At its most initial stage, HCQ/ CQ drugs are able to hinder ACE2 terminal glycosylation, which inhibits the entry of SARSCoV-2 virus (Vincent et al., 2005). Next, HCQ/ CQ can disable viral replication by providing a non-suitable condition (increase in endosomal $\mathrm{pH})$ needed for host-virus cell infusion through endocytosis and annulment of virus-endosome fusion (Sharma et al., 2020, Eynde, 2020). Apart of that, $\mathrm{HCQ} / \mathrm{CQ}$ are also capable of restricting post-translational modification of proteins that may lead to the inhibition of the SARS-CoV-2 virion (Uzunova et al., 2020). In addition, HCQ/
CQ may also be able to prevent SARS-CoV-2 intracellular polymerization and lower the level of cytokines in SARS-CoV-2 infected patients (Sharma et al., 2020). Inhibition by blocking the sialic acid receptors is also another mode of action proposed through the use of HCQ/CQ (Satarker et al., 2020). Contrarily, Remdesivir functions by targeting the activity of viral RdRp while the drugs Lopinavir/Ritonavir may result in the production of immature virus particles, however, more studies on Lopinavir/Ritonavir may be needed to confirm its effectiveness in preventing the infection of SARS-CoV-2 virus in humans (Gordon et al., 2020, Weller et al., 2001). The schematic representation of mechanism of action for all treatment drugs discussed can be seen in Figure 1 and Figure 2.

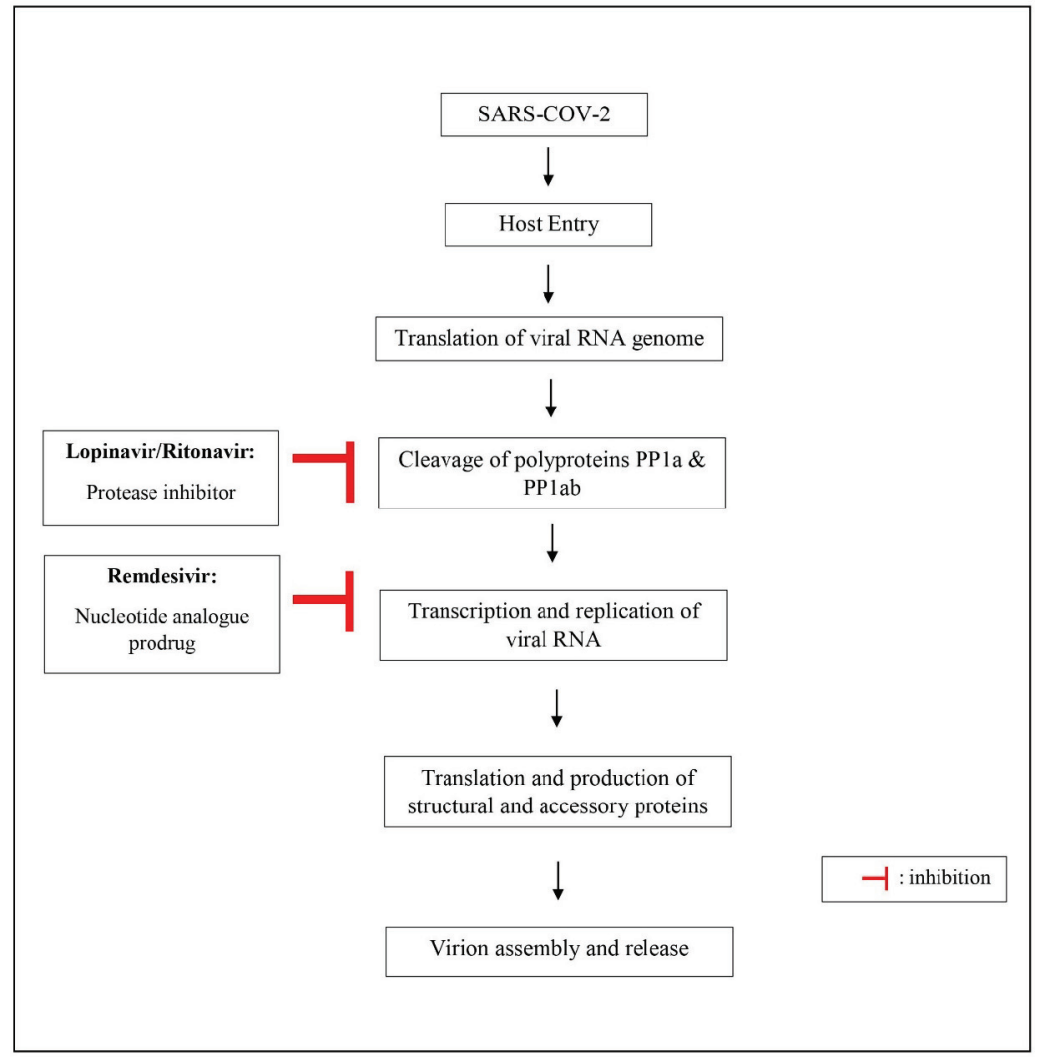

Figure 1: Schematic representation of mechanism of action for Remdesivir and Lopinavir/Ritonavir against SARS-CoV-2 (Uzunova et al., 2020) 


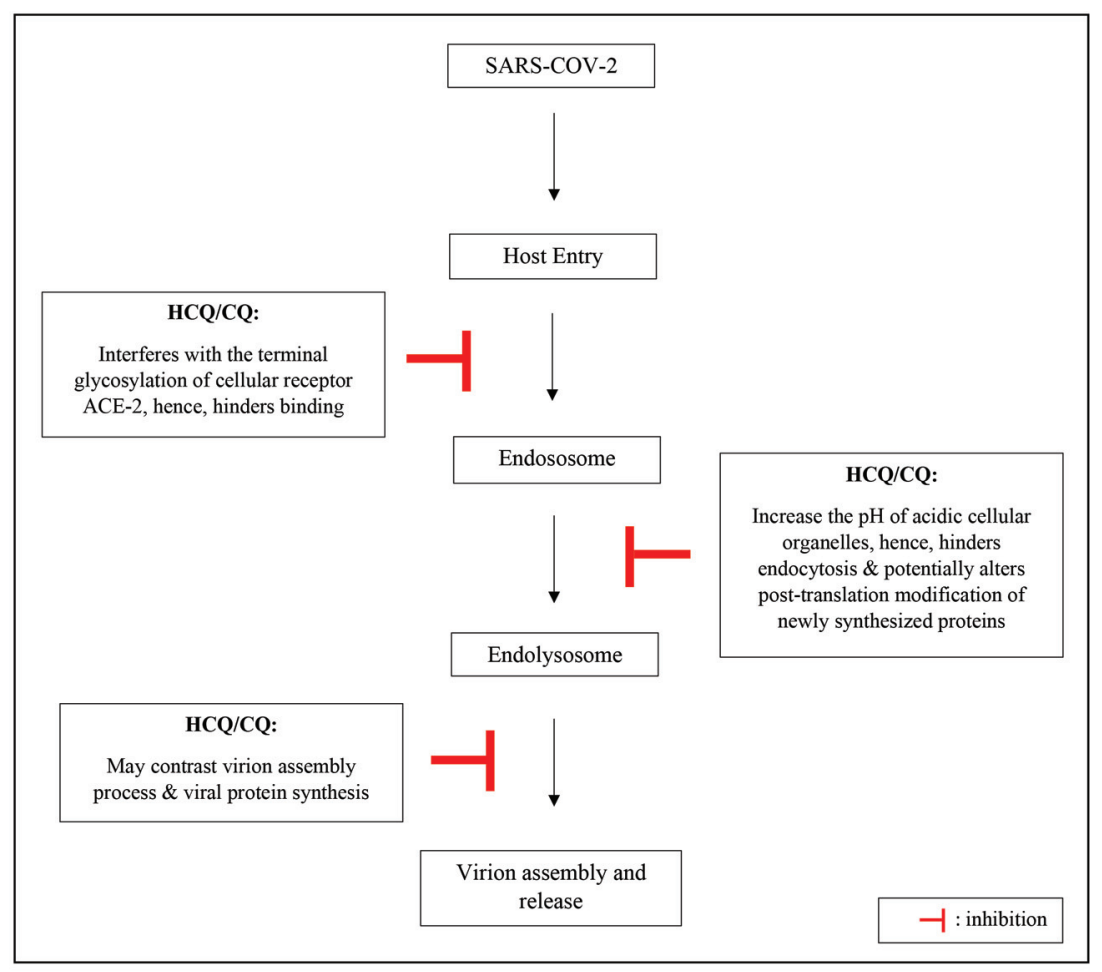

Figure 2: Schematic representation of mechanism of action for chloroquine/hydroxychloroquine against SARS-CoV-2 (Adapted from Cortegiani et al., 2020)

Current Status of Potential Drugs under Trials

Currently, more than 200 drugs and drug combinations are being tested on patients and results based on the best form of evidence has been recorded (US National Library of Medicine, 2020a). Among the vast number of drug trials, information on the drugs prioritized by WHO in the treatment of SARS-CoV-2 have been focussed in this review. The Remdesivir is a repurposed therapeutic antiviral drug that has been recommended by experts through a wide range of analysis. Remdesivir has been observed to be potentially effective to inhibit SARSCoV-2 with almost no or minimum adverse effects (Wang et al., 2020b, Holshue et al., 2020, Choy et al., 2020). Several successful attempts on inhibiting Middle East respiratory syndrome (MERS-CoV) and severe acute respiratory syndrome coronavirus (SARS-CoV) shows the potential of remdesivir to be effective on SARSCoV-2 as well (Sheahan et al., 2020, Wang et al., 2020b, Agostini et al., 2018). Remdesivir was also nominated as a preferential drug for clinical treatment to be tested as a trusted antiviral therapy option (Alexander et al., 2020). Although assumed potentially successful, Remdesivir has to be further tested in terms of safety and efficacy before declaring it an official cure. The first clinical trial of Remdesivir was reported a failure, however, a final conclusion regarding the effectiveness of this drug had not been made due to arising debates among researchers on its trial procedures (New Straits Times, 2020).

The therapy of Lopinavir/Ritonavir is also being considered as reduced mortality, shortened ICU and hospital stay were seen during trials, and chest CT scans showed the minimum of promise for it to be used in treating patients with SARS-CoV-2 (Deng et al., 2020, Dorward J. \& Gbinigie K. 2020, Ampel., 2020). A combination of the therapy with Arbidol had also been 
suggested to yield better results (Deng et al., 2020). This drug, however, was perceived as a negatively inclined treatment as it also produced insignificant results with almost no difference even in primary outcomes (Cao et al., 2020a, Cao et al., 2020b). It was further suggested that Lopinavir/Ritonavir was to be used within ten days of symptoms appearance (Yan et al., 2020). It was also reported that gastrointestinal adverse effects were observed when the drug was used on patients (Cao et al., 2020b). Hence, the status of Lopinavir/Ritonavir as a potential successful treatment is also still debatable.

The drug combination of Lopinavir/ Ritonavir with IFN- $\alpha$ and Lopinavir/Ritonavir with IFN- $\beta$ are used to treat relapsing multiple sclerosis and previous SARS-CoV and MERS$\mathrm{CoV}$ respectively: a. No studies were however reported to have been done on these drug combinations.

Being an antimalarial drug, many studies have shown positive viral efficacy and safety during trials on Chloroquine (Cheepsattayakorn A.\& Cheepsattayakorn R, 2020, Gao etal.,2020b, Wang et al., 2020b, Colson et al., 2020). The use of Chloroquine was nevertheless questioned for its credibility of treating critical ICU patients of SARS-CoV-2 based on least convincing clinical data, antiviral abilities and trials (Taccone et al., 2020). Apart from that, studies have shown improvement in the condition of SARS-CoV-2 patients administered with hydroxychloroquine (Chen et al., 2020, Lane et al., 2020, Tang et al., 2020). However, a study in China opposed the usage of hydroxychloroquine as it might not help in curing SARS-CoV-2 patients and may cause more severe adverse effects in return (Frellick, 2020). Thus, the credibility of hydroxychloroquine as a therapeutic drug is also still unknown until a proper trial is done.

Nevertheless, several other studies also recommended a range of drugs for the treatment of SARS-CoV-2. The first review on the therapeutics used on SARS-CoV-2 patients suggested that studies on corticosteroid therapy was the most focused followed by studies on Lopinavir and then Oseltamivir (Tobaiqy et al., 2020). Other drugs for treatment include the antiviral EIDD-2801, Japan flu drug, Tocilizumab, and Losartan (LiveScience, 2020a). All the drugs tested on SARS-CoV-2 are still in trial stages and have produced many pros and cons to be considered for efficient use. A combination of antiviral drugs as treatment, such as anticoagulant therapy with heparin and statins with angiotensin II type I receptor blockers (ARB) had also been suggested (Tang et al., 2020, Fedson et al., 2020). No treatment has been finalized to be able to treat SARSCoV-2 patients. The summary of information on prioritized drugs can be seen in Table 2 . 


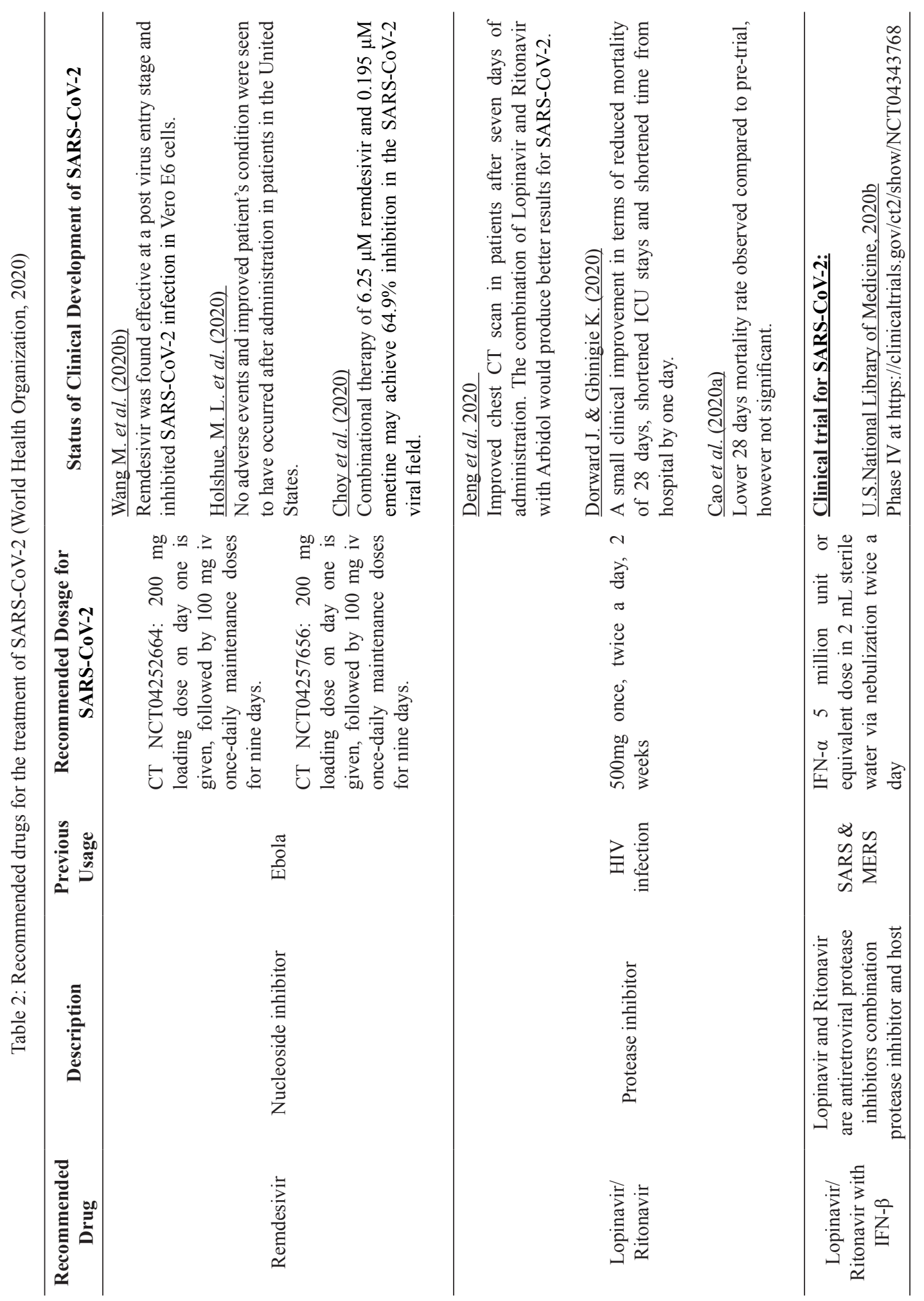




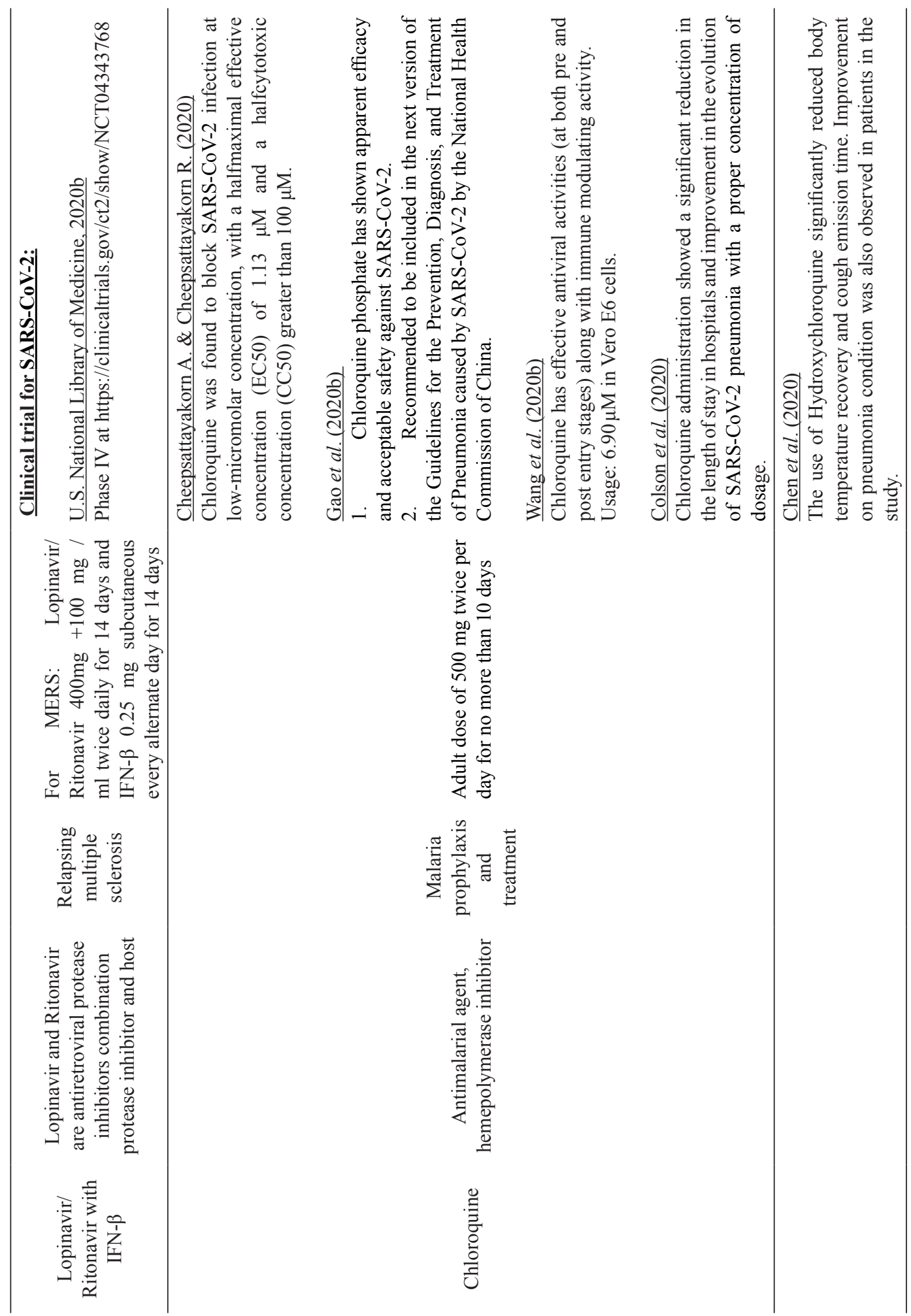


Alternative Treatment Methods against SARS$\mathrm{CoV}-2$

Recently, researchers have proposed convalescent plasma therapy for patients severely affected by SARS-CoV-2. Convalescent plasma therapy was observed to increase or maintain neutralizing antibodies to work against the SARS-CoV-2 virus, reduce clinical symptoms in about three days along with a positive but varying rate of absorption of lung lesions seen through radiological examination (Duan et al., 2020). Additionally, this therapy showed no distinct adverse effects and also showed reactions that give rise to the elimination of SARS-CoV-2 virus in patients tested with throat swab (Ye et al., 2020). Several patients at different levels of infection were also observed to improve after treatment with this therapy, leading to them being discharged from hospital (Shen et al., 2020). Early administration of this therapy has been said to promote higher effectiveness level in eliminating the virus (ElAziz \& Stockand, 2020). This discovery can be considered to have the most potential so far, however, more clinical trials involving a variety of patients can determine the ultimate outcome.

Apart from that, research on bioactive molecules extracted from natural molecules and products, as well as natural lead compounds, have also shown positive contribution as potential inhibitors against the SARS-CoV-2 virus. Findings on bioactive molecules function as an alternative to the limited therapeutics available against SARS-CoV-2 and might be proven effective following further clinical trials and testing. These bioactive molecules are known to work against the main protease (Mpro), one of the drug targets of SARS$\mathrm{CoV}-2$. Out of 65 potential bioactive molecules, Oolonghomobisflavan-A, extracted from the tea plant (Camellia sinensis) had been highlighted as a potential lead molecule that can inhibit the Mpro of the SARS-CoV-2 virus due to its good number of hydrogen bonds and higher Mechanic/Poisson-Boltzmann Surface Area (MM-PBSA) binding energy with Mpro (Bhardwaj et al., 2020b). In another study, six 
out of ten polyphenols, namely broussochalcone A, papyriflavonol A, 3'-(3-methylbut-2-enyl)3', 4',7-trihydroxyflavane,

broussoflavan

$\mathrm{A}$, kazinol $\mathrm{F}$ and kazinol $\mathrm{J}$, extracted from Broussonetia papyrifera have exhibited stronger binding ability with Mpro, thus recommended as potential inhibitors against SARS-CoV-2 (Ghosh et al., 2020).

Similarly, using the in-silico approach on 15 flavonoid based phytochemicals, researchers have suggested three polyphenols, namely, rutin (readily available as a drug), isorhamnetin-3$\mathrm{O}-\beta-\mathrm{D}$, calendoflaside, derived from Calendula officinalis, to be effective inhibitors of the Mpro through their assessment on binding affinity, stability and flexibility of the phytochemicals with the Mpro of SARS-CoV-2 virus (Das et al., 2020). Furthermore, polyphenols, such as EGCG, theaflavin-3'-O-gallate (TF2a), theaflavin-3'gallate (TF2b), theaflavin 3,3'-digallate (TF3), which have been widely used for therapeutic effects for several diseases, have been tested effective based on their strong ability to bind to the RNA-dependent RNA polymerase (RdRp) of SARS-CoV-2 and aid in the inhibition of RdRp (Singh et al., 2020). These findings have been further confirmed by the MM-PBSA calculation and through the analysis of druggability, hence found effective to be used as a therapy against the SARS-CoV-2 virus (Singh et al., 2020). As alternatives, the compounds highlighted above can be potentially successful to combat the SARS-CoV-2 virus, though many further trials would be required to properly test the antiviral properties of polyphenols against SARS CoV-2.

\section{Factors Influencing the Effectiveness of Antiviral Treatment}

An antiviral drug usually works by aiming for molecular targets in every possible stage of a virus life cycle. Although antiviral treatment has been developed since the 1980s to overcome HIV infection, many more new and advanced drugs are still in the process of development against coronaviruses, dengue, filoviruses and many others (Ryu, 2017, Richman \& Nathanson, 2016). An effective antiviral treatment will usually display high rates of safety in the treatment used, low cost and adequate supply of the particular drug (Mitja, 2020). Currently, development of antiviral treatment is being studied for the newly emerged SARS-CoV-2 viral disease, and there are many factors that can influence the effectiveness of a particular antiviral treatment, hence, influencing the rate of availability of the antiviral treatment needed.

The most important factor that influences the effectiveness of an antiviral treatment against SARS-CoV-2 is the safety of the treatment towards patients and the absence of adverse effects post-treatment. Based on suggested antiviral drugs listed above, the trials involving Remdesivir, were related to cause constipation, nausea, diarrhea, vomiting, poor appetite and increased levels of liver enzyme (Fan et al., 2020b). Ribavarin and Lopinavir/ Ritonavir showed adverse effects, such as, reduction of haemoglobin, which causes respiratory distress and gastrointestinal adverse effects, namely, nausea, vomiting and diarrhoea respectively (Martinez, 2020, Jean et al., 2020). Chloroquine was observed to cause effects on hepatic, hematologic and renal systems with a major shortage of antimalarial armamentaria and was not recommended for use, while hydroxychloroquine was not recommended to those with allergy to hydroxychloroquine, pregnant and breastfeeding mothers (Cortegiani et al., 2020b, Gautret et al, 2020). The adverse effects reported currently influence the effectiveness of the antiviral drugs for administration, hindering proper utilization of one or more drugs as the cure for patients infected with SARS-CoV-2. This in return also slows down the process of finalizing the antiviral drug to treat SARS-CoV-2.

The massive demand for antiviral drugs that have been repurposed for the use against SARS$\mathrm{CoV}-2$ serves as a challenge as complaints have been filed against the shortage of Remdesivir supply in the United States (Ledford, 2020). The distribution capacity of this antiviral drug to every country is also doubted (Bai, 2020). While potential antiviral drugs are already being 
used by researchers worldwide for clinical trials against SARS-CoV-2, the use of the same drugs to treat existing diseases other than SARS-CoV-2 are still ongoing. This affects the supply of antiviral drugs needed and demand is yet to be met. Apart from that, patients with cerebrovascular diseases and diabetes have been reported to be the ones who usually die even with treatment (Yang et al., 2020). Hence it is also difficult to propose an antiviral drug that is suitable for both readily healthy and ill patients infected with SARS-CoV-2.

Likewise, other factors such as the time lag between diagnosis and antiviral treatment prescribed to treat SARS-CoV-2 patients using repurposed drugs can also affect the effectiveness of the antiviral treatment (Smith et al., 2020). The viral kinetic profile for each virus type varies, and in the case of SARS-CoV-2, it is suggested that the peak is estimated to occur eight to 10 days after infection (Smith et al., 2020). When treatment is not initiated accordingly, the drug may no longer work to eliminate the virus. For example, an influenza infection will have to be treated within three days of its first appearance of symptoms in order to work effectively, where any prolonged duration might reduce the efficiency of the drug used (Aoki et al., 2003). There is a chance of more than $50 \%$ of efficacy if treatment is initiated prior to symptoms onset, however, this might also not work on patients with severe illness (Goncalves et al., 2020). This can only be achieved when patients report for swab testing right away upon recognition of symptoms, which might be challenging if the public fail to identify symptoms correctly or intentionally stay away from being tested.

The optimization of dosage used to treat SARS-CoV-2 patients using repurposed drugs plays a role in hindering the effectiveness of a drug as well. For this, it is important to take note and understand the potency of drugs before establishing them to patients (Smith et al., 2020). Hydroxychloroquine was found to be more potent than Chloroquine, suggesting different dosage requirements to be followed as compared to Chloroquine for effective treatment and recovery (Yao et al., 2020). Similar effort should be taken on the available drugs every now and then to ensure optimized dosage when treating patients with SARS-CoV-2 for better chances of recovery.

The emergence of SARS-CoV-2 virus is extremely new and requires more studies to be carried out in order to completely understand the virus. Thus, the unknown aspects that are yet to be discovered can hinder the process of introducing a proper antiviral treatment to the public as in the demanded period. The development of a treatment against SARS$\mathrm{CoV}-2$ can be based on the previously identified SARS-CoV virus, however, the differences in some molecular aspects and the extent of its effects towards humans is questionable (Ceccarelli, 2020). Discovering an ultimate treatment might be challenging and cannot be developed too soon; efforts to combat SARSCoV-2 must be ongoing.

\section{Potential Vaccines Development for SARS- CoV-2}

Vaccines are being developed to prevent the spread of SARS-CoV-2 to healthier populations across the globe. An international effort using randomized trials of potential vaccine candidates has been introduced to aid an effective, reliable and appropriate development of vaccines with a global standard (World Health Organization, $2020 \mathrm{~b}$ ). Vaccines are also in the process of development partially based on the responses to Ebola and SARS (UNICEF, 2020). Clinical trials on potential candidates of vaccine from different types of vaccine platforms are carried out in several countries around the world. Currently, a total of six candidate vaccines from four vaccine platforms were reported to have entered clinical evaluation while an increased number of 77 candidate vaccines were reported to be in the preclinical evaluation (World Health Organization, 2020d). Trials using new candidate vaccines are emerging rapidly, entering the clinical and preclinical stages respectively. Candidate vaccine platforms consist of non-replicating viral vectors, deoxyribonucleic acid (DNA), ribonucleic 
acid (RNA), inactivated, live attenuated virus, protein subunits, replicating viral vectors, viruslike particles (VLP) and also unknown platforms (World Health Organization, 2020d). A total of 83 vaccine candidates nominated from the vaccine platforms listed above had been used for the vaccine development trials. Candidate vaccines from protein subunits platforms were observed to be used the most while live attenuated platforms were least used for trials among all other platforms as seen in Figure 3. Candidate vaccines from non-replicating viral vectors and RNA vaccine platforms were equally nominated for trials. Candidate vaccines among inactivated, VLP and unknown platforms are seen to be used in small numbers probably due to its least suitable properties to prevent the replication of SARS-CoV-2 virus in humans. Candidate vaccines from the remaining DNA and replicating viral vectors platforms are seen to be nominated for trials in moderation, ranging from $10 \%$ to $12 \%$ of total percentage of usage.

Among all the vaccine candidates used, the six candidate vaccines that have been observed to enter clinical evaluation stage are from the nonreplicating viral vector, DNA, inactivated and RNA vaccine platforms as seen in Table 3. All candidate vaccines tested in this clinical stage were tested for the development of vaccines for several other diseases except for the inactivated vaccine candidate that has not been tested for any other previously occurred viral diseases. The candidate vaccines are most likely to have varying advantages and tested for a promising outcome. For instance, platforms of mRNA and DNA were reported to offer flexibility such as antigen manipulation and potential speed, whereas viral vector platforms usually have higher levels of protein expression along with durable stability and highly induced immune responses (Le at al., 2020). Adjuvants are also recorded to be aiding in the enhancement of immunogenicity in which, vaccine developers such as GlaxoSmithKline have been working on, to be used along with vaccines developed by researchers (Le at al., 2020). All reported candidate vaccines are evaluated for safety and immunogenicity along with tolerability and persistence.

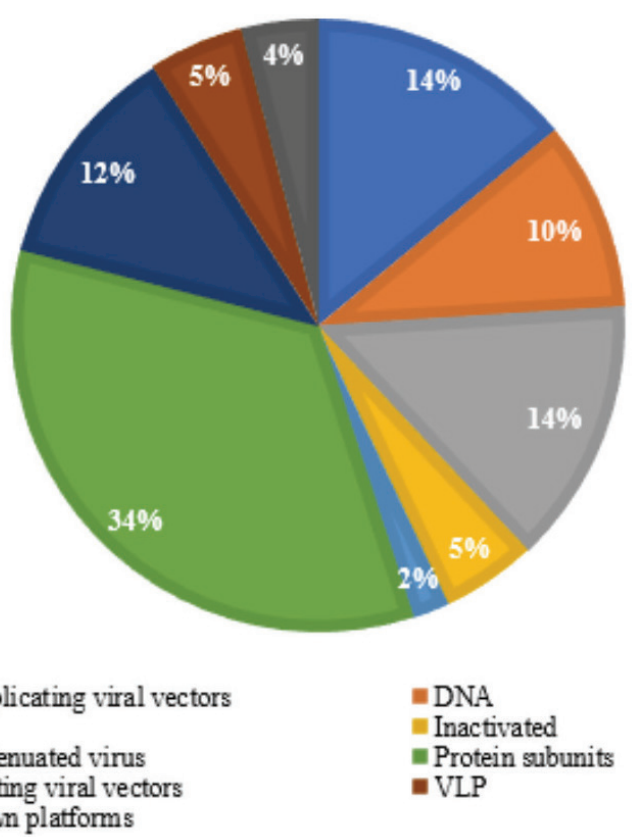

Figure 3: The percentage of vaccine platforms used for the development of a potential universal vaccine against SARS-CoV-2 (World Health Organization, 2020) 
Non-replicating vectors are usually vaccine platforms that are known to be safe with a long history of usage for gene therapy and are present in multiple serotypes and chimeric forms, where Adenoviruses are considered the most widely utilized vectors for vaccine development (Robert-Guroff, 2007). As such, candidate vaccines mainly used for development against SARS-CoV-2 under the non-replicating vectors platform are the Adenovirus Type 5 Vector and chAdOx1. Adenovirus Type 5 Vector is made from a weakened common cold adenovirus that normally affects chimpanzees, while chAdOx 1 is an adenovirus that infects humans, with longer lasting immune responses (U.S Department of Health and Human Services, 2020, LiveScience, 2020b). Currently, both vaccine candidates have been showing satisfying results through the development of neutralizing antibodies and T-cells responses in the majority of their participants with mild adverse reactions. As a result of successful trials from Phase I and Phase II studies, both vaccine candidates have been allowed to proceed to Phase III of clinical stage evaluation (University of Oxford, 2020, Bar-Zeev et al., 2020, Zhu et al., 2020, Folegatti et al., 2020).

The inactivated vaccine platforms on the other hand, are dead pathogen versions as opposed to live, weakened virus vaccines which may not necessarily be as protective as live vaccines and need booster shots in between for continued protection against SARS-CoV-2 (U.S Department of Health and Human Services, 2020). Both vaccines using the inactivated vaccine platform had been also displaying promising results as both vaccines highlighted the development of antibodies against SARSCoV-2 with no serious adverse effects (LiveScience, 2020b). The inactivated vaccine candidate trial was reported to be further carried out on children and the vaccine had also been claimed to be used by the employees of the developer while the inactivated vaccine with alum as placebo had already begun their Phase III clinical trials in Abu Dhabi (Liu et al., 2020, Barrington et al., 2020).
In contrast to the traditional vaccine development as above, the RNA vaccine platform consists of a first-hand quick and easily manufactured technology based vaccine candidate made up of a genetic material known as messenger RNA (mRNA) that triggers the immune system $\backslash$ when naturally exposed to the virus, similar to the traditional vaccine candidates above (LiveScience, 2020b). Although the use of these vaccines was earlier opposed as it was considered unsafe and ineffective, the mRNA vaccine candidate had showed positive results and minimal adverse effects when used against SARS-CoV-2 through the development of a strong immune response when tested in rhesus macaque monkeys (Pardi et al., 2018, Jackson et al., 2020). This result, however, varied from the outcome produced through chAdOx1, where rhesus macaque monkeys were only observed to be immune against pneumonia and not SARS-CoV-2 (Corbett et al., 2020). The DNA vaccine platform, known to be the only nucleicacid based vaccine, has notable advantages such as being inexpensive, providing longer immunogenicity, easy development and storage (Alarcon et al., 1999, Sasaki et al., 2003, Khan et al., 2009, Khan, 2013). This vaccine has been reported to produce positive results in its Phase I clinical trial, where antibodies detected displayed negative binding to $\mathrm{S}$ protein with the ACE2 receptor of SARS-CoV-2 and will begin its second and third phase of trials once regulatory concurrence is obtained (Smith et al., 2020, Inovio Pharmaceuticals, 2020).

The developers of these vaccines are also seen to be more varied through the involvement of small-scale, institutional developers. Additionally, five out of six candidate vaccines are observed to be used among healthy adults aged 18 to approximately 60 years old. Candidate inactivated virus vaccine was observed to target a wider age range; reportedly from as young as six years old and above. Based on the data given, the candidate Adenovirus Type 5 Vector vaccine has also been in Phase 2 clinical evaluation, that typically focuses on gathering preliminary data on the efficacy of the vaccine on people with underlying medical conditions while the rest 


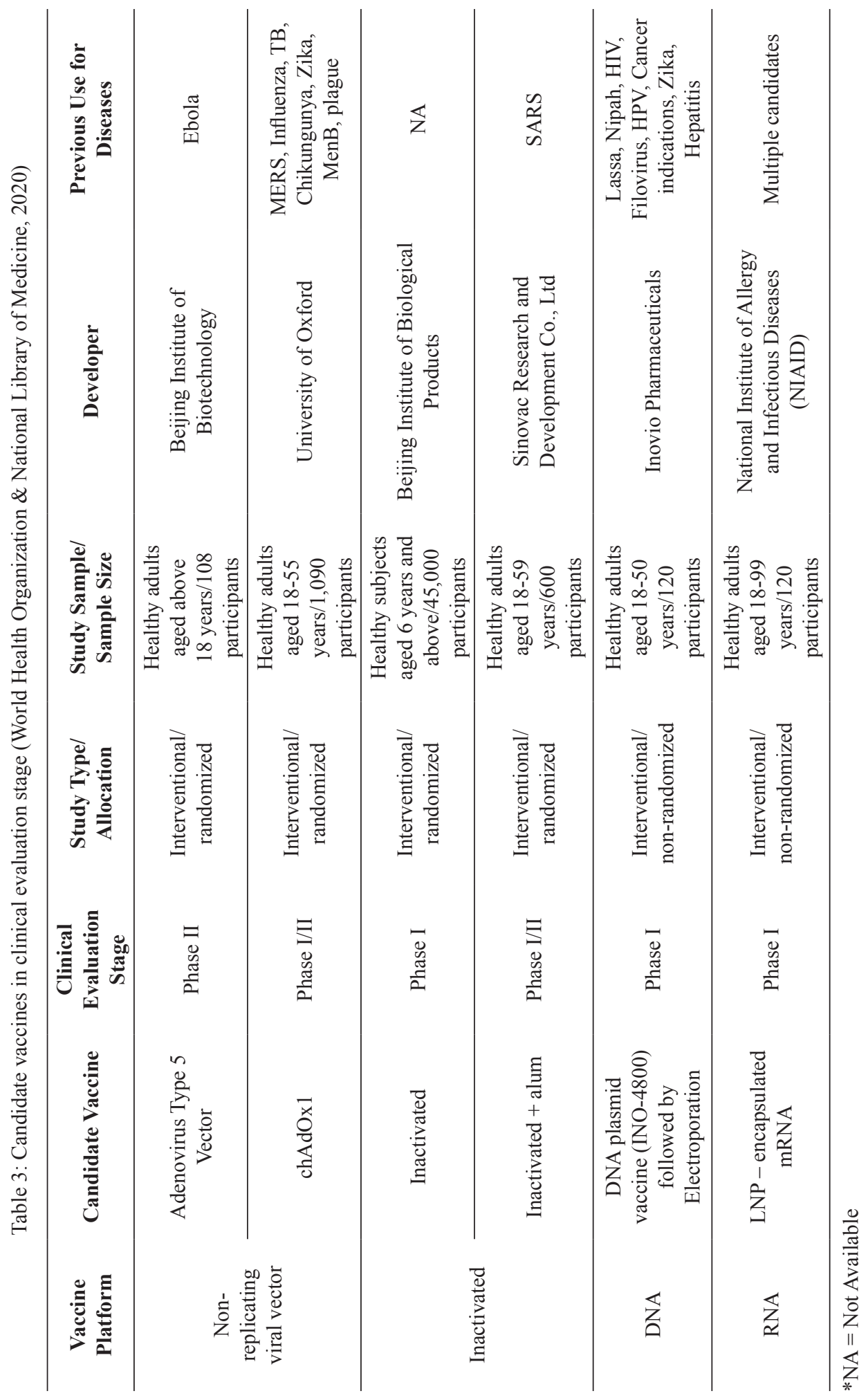


of them are still in Phase 1 for safety testing among healthy individuals. The development of candidate vaccines to prevent SARS-CoV-2 is still under process as the candidates would have to fulfil safety and efficacy measures and should be able to cover patients under different conditions and health complications.

The development of a vaccine is time consuming and would require much more research to produce a universal vaccine for the entire human population. Nevertheless, it was reported that a genetic engineering method using DNA and RNA that hold instructions for faster vaccine productions compared to the conventional techniques was used (Schmidt et al., 2020). However, the efficiency of this method developed during the MERS outbreak is still unclear. Recently, a pilot study involving a purified inactivated SARS-CoV-2 virus vaccine candidate (PiCoVacc) tested on animal models resulted in complete and partial protection against SARS-CoV-2 (Gao et al., 2020b). Today, as positive as it sounds, there is still no evidence that the same result can be expected from humans, where the vaccine would need more trials to confirm similar or better results without imposing any risk of adverse effects. Hence, in the meantime, the public are advised to adhere to proper prevention measures to stay safe from the infection of SARS-CoV-2.

\section{Challenges and Time Constraints in Vaccine Development}

Although vaccine development is being accelerated, there are many challenges in developing an effective vaccine for everyone. These challenges include improper understanding of immune responses to infection, mediocre marketing abilities especially in poorer countries, insufficient financial facilities, safety and efficacy factors, ineffective patent protection and regulation and the absence of proper health coverage worldwide (Oyston \& Robinson, 2012, Kaufmann et al., 2014, Possas et al., 2019). Hence, the need to strategize on the development of improved next-generation vaccines is highly important to overcome existing pandemics (Wei et al., 2020). In addition to the challenges faced, the lack of trust in vaccine safety and the adverse effects that may be caused by vaccination have also hindered active manufacturing and distribution of these vaccines, restricting access to vaccines in many countries (Geoghegan et al., 2020).

As such, vaccine development against SARS-CoV-2 virus is also burdened by several circumstances that require proper consideration before declaring the vaccine to the public. One such example may lie within the antigenic target and vaccine related disease aggravation (Nick et al., 2020). Based on research on SARS-CoV, this is directly associated with concerns over antibody-dependent enhancement (ADE) from the phenomenon of enhanced pathogenesis through the activation of macrophages via the antibody's Fc domain, where ADEs are known to accumulate over time, with increased severity of risk with age (Nick et al., 2020, Jianqing, 2020). Since the SARS-CoV-2 is known to have close homology with SARS-CoV, this aspect can be expected to be a challenge as well (Chan et al., 2020). Apart from that, the development of a vaccine might also engender the enhanced respiratory disease exacerbation (ERD) as reported in the formaldehyde-inactivated vaccine development against respiratory syncytial virus (FI-RSV), if implemented for SARS-CoV-2 (Nick et al., 2020). Vaccine's testing using animal models could also help in enhancing immunity against SARS-CoV-2, however, the unknown immune response and adverse effects that may be caused is the underlying challenge as human physiology and characteristics of immune response is different and more complex than animals (Saif, 2020). It is also observed to be difficult to gather all aspects and elements needed for more intense studies using animal models as only limited laboratories are used to isolate live strains of SARS-CoV-2 (Jianqing, 2020).

Altogether, clinical safety and efficacy of a vaccine towards human health was considered the most difficult challenge to overcome in developing trusted vaccines (Calina et al., 
2020). A suitable candidate vaccine to overcome SARS-CoV-2 virus with minimum or almost no severe adverse effects is still difficult. For example, a review that was based on the experience reported from pioneer Chinese experts in handling the virus, suggested that the use of inactivated virus vaccine candidates might leave immunopathological enhancement effects and need long-term and careful deployment (Huaiyu, 2020). This could be used by anti vaxxers to strengthen their beliefs, leaving healthcare professionals with a greater challenge to influencethe public to get vaccinated. This is because not everyone vaccinated can truly be immune to this disease due to the varying genetic and immunological aspects (Colgrove, 2007). Ample of clinical trials and laboratory analysis would be required to produce a vaccine that will be safe for every human being, globally. This would in return, consume more time to develop a proper vaccine. Factors such as age and the time frame or duration of vaccine response can also impact the efficacy of the vaccine (Lord, 2013, Boda et al., 2018).

Apart from that, other important factors, such as the technology used for vaccine development and capacity for large-scale production of vaccines are also challenges (Calina et al., 2020). Technology may have to be updated thus, requiring more trial and error. Furthermore, in a situation where if a vaccine is properly developed, the lack of commerciality in SARS-CoV-2 vaccines would leave manufacturers exhausted because of largescale new vaccine production at the expense of previously produced vaccines needed for other diseases. (Calina et al., 2020). Hence, the development and manufacturing of a vaccine is not easy and needs thorough research and trials due to the long list of challenges. More time to make concrete findings is needed from initial development to the final stage, involving implementation policies.

\section{Conclusion}

Several combinations of treatment and vaccine approaches are constantly being tested by researchers. Health authorities and researchers are still dependent on currently available therapeutic efforts to help cure infected patients as an effective vaccine is yet to be finalized. However, the efficiency of a treatment varies according to the state of health of an individual, while vaccine development usually takes many approved trials at several levels before rolled out to the public, making it more challenging with the limited time available. This is because SARS-CoV-2 is a novel viral disease that needs more research to be done to effectively overcome the pandemic. While treatment and vaccine development are ongoing, it is important to practice prevention guidelines, such as physical distancing, frequent washing of hands, use of sanitizers, restraining movements such as travelling and avoiding unnecessary close contact. Although challenging, this new norm must be adapted to limit the spread of the disease and if possible, to completely overcome SARS-CoV-2 in the near future.

\section{Acknowledgements}

This work was supported by the PPSK - KPI Research Incentive 4.0 Fund (1001/PPSK/ AUPS001), Universiti Sains Malaysia (USM).

\section{References}

Agostini, M. L., Andres, E. L., Sims, A. C., Graham, R. L., Sheahan, T. P., Lu, X., Smith, E. C., Case, J. B., Feng, J. Y., Jordan, R., Ray, A. S., Cihlar, T., Siegel, D., Mackman, R. L., Clarke, M. O., Baric, R. S., \& Denison, M. R. (2018). Coronavirus susceptibility to the antiviral remdesivir (GS-5734) is mediated by the viral polymerase and the proofreading exoribonuclease. American Society for Microbiology. https//:doi. org/10.1128/mBio.00221-18.

Alarcon, J. B., Waine, G. W., \& McManus, D. P. (1999). DNA vaccines: technology and application as anti-parasite and anti- 
microbial agents. Advances in Parasitology. 42, 343-410.

Alexander, B., Schooneveld, T. V., Stohs, E., Rupp, M., Marcelin, J., Bergmann, S., \& Hankins, R. (2020). COVID-19 Antiviral and Pharmacotherapy Information. Nebraska Medicine.

Aoki, F. Y., Macleod, M. D., Paggiaro, P., Carewicz, O., El Sawy, A., Wat, C., Griffiths, M., Waalberg, E., \& Ward, P. (2003). Early administration of oral oseltamivir increases the benefits of influenza treatment. Journal of Antimicrobial Chemotherapy, 51(1), 123-129.

Bai, N. (2020). Antiviral drug Remdesivir can help fight the Coronavirus, but can patients get it? University of California, San Francisco.

Bar-Zeev, N., \& Moss, W. J. (2020). Encouraging results from phase $1 / 2$ COVID-19 vaccine trials. The Lancet. https//:doi.org/10.1016/ S0140-6736(20)31611-1.

Barrington, L., \& Cornwell, A. (2020). China's Sinopharm begins late stage trial of COVID-19 vaccine in UAE. Reuters.

Bhardwaj, V. K., Singh, R., Das, P., \& Purohit, R. (2020a). Evaluation of acridinedione analogs as potential SARS-CoV-2 main protease inhibitors and their comparison with repurposed anti-viral drugs. Computers in Biology and Medicine. https://doi. org/10.1016/j.compbiomed.2020.104117.

Bhardwaj, V. K., Singh, R., Sharma, J., Rajendran, V., Purohit, R., \& Kumar, S. (2020b).

Identification of bioactive molecules from tea plant as SARS-CoV-2 main protease inhibitors. Journal of Biomolecular Structure and Dynamics. https//:doi.org/10 $.1080 / 07391102.2020 .1766572$.

Boda, D., Docea, A. O., Calina, D., Ilie, M. A., Caruntu, C., Zurac, S., Neagu, M., Constantin, C., Branisteanu, D. E., Voiculescu, V. et al. (2018). Human papilloma virus: Apprehending the link with carcinogenesis and unveiling new research avenues (Review). International Journal of Oncology, 52, 637-655.

Cai, Q., Yang, M., Liu, D., Chen, J., Shu, D., Xia, J., Liao, X., Gu, Y., Cai, Q., Yang, Y., et al. (2020). Temporary removal: Experimental treatment with Favipiravir for COVID-19: An open-label control study. Engineering. https//:doi.org/10.1016/j.eng.2020.03.007.

Calina, D., Docea, A. O., Petrakis, D., Egorov, A. M., Shmukhametov, A. A., Gabibov, A. G., Shtilman, M. I., Kostoff, R., Carvalho, F., Vinceti, M., Spandido, D. A. et al. (2020). Towards effective COVID-19 vaccines: Updates, perspectives and challenges (Review). International Journal of Molecular Medicine, 46, 3-16.

Caly, L., Druce, J. D., Catton, M. G., Jans, D. A., \& Wagstaff, K. M. (2020). The FDA-approved Drug Ivermectin inhibits the replication of SARS-CoV-2 in vitro. Antiviral Research. https//:doi. org/10.1016/j.antiviral.2020.104787.

Cao, B., Baden, L. R., \& Rubin, E. J. (2020a). Lopinavir-Ritonavir was not effective for COVID-19. NEJM Journal Watch.

Cao, B., Wang, Y., Wen, D., Liu, W., Wang, J., Fan, G., Ruan, L., Song, B., Cai, Y., Wei, M., et al. (2020b). A trial of LopinavirRitonavir in adults hospitalized with severe Covid-19. The New England Journal of Medicine, 382, 1787-1799.

Cascella, M., Rajnik, M., Cuomo, A., Dulebohn, S. C., \& Di Napoli, R. (2020). Features, evaluation and treatment coronavirus (COVID-19). StatPearls Publishing.

Centres for Disease Control and Prevention. (2018). Understanding how vaccines work. U.S Department of Health and Human Services.

Ceccarelli, M., Berretta, M., Rullo, E. V., Nunnari, G., \& Cacopardo, B. (2020). Editorial-Differences and similarities between Severe Acute Respiratory Syndrome (SARS)-CoronaVirus (CoV) 
and SARS-CoV-2. Would a rose by another name smell as sweet? European Review for Medical and Pharmacological Sciences, 24, 2781-2783.

Chan, J. F., Kok, K. H., Zhu, Z., Chu, H., To, K. K., Yuan, S., \& Yuen, K. Y. (2020). Genomic characterization of the 2019 novel human-pathogenic coronavirus isolated from a patient with atypical pneumonia after visiting Wuhan. Emerging Microbes and Infections, 9(1), 221-236.

Chang, C. K., Lo, S.C., Wang, Y. S., \& Hou, M. H. (2016). Recent insights into the development of therapeutics against coronavirus diseases by targeting $\mathrm{N}$ protein. Drug Discovery Today, 21(4), 562-572.

Cheepsattayakorn, A., \& Cheepsattayakorn, R. (2020). Novel Therapeutic interventions in treating patients with COVID-19 pneumonia, COVID-19 acute respiratory syndrome and severe COVID-19 illness and promising vaccine candidates. Acta Scientific Microbiology, 3(5), 97-99.

Chen, Z., Hu, J., Zhang, Z., Jiang, S., Han, S., Zhuang, R., Hu, B., \& Zhang, Z. (2020). Efficacy of hydroxychloroquine in patients with COVID-19: Results of a randomized clinical trial. Medrxiv Preprints. https://doi. org/10.1101/2020.03.22.20040758.

China National Health Commission. (2020). Novel coronavirus diagnosis and treatment plan (7th ed.). The People's Republic of China.

Choy, K-T., Wong, A.Y-L., Kaewpreedee, P., Sia, S. F., Chen, D., Hui, K. P. Y, Chu, D. K. W., Chan, M. C. W., Cheung, P. P-H., Huang, X., Peiris, M., \& Yen, H-L. (2020). Remdesivir, lopinavir, emetine, and homoharringtonine inhibit SARS-CoV-2 replication in vitro. Antiviral Research. https://doi. org/10.1016/j.antiviral.2020.104786.

Colgrove, J. (2007). Immunity for the people: The challenge of achieving high vaccine coverage in American history. Public Health Reports, 122, 248-257.
Colson, P., Rolain, J-M., Lagier, J-C., Brouqui, P., \& Raoult, D. (2020). Chloroquine and hydroxychloroquine as available weapons to fight COVID-19. The Journal of Infection. https://doi.org/10.1016/j. ijantimicag.2020.105932.

Corbett, K. S., Flynn, B., Foulds, E. K., Francica, J. R., Boyoglu-Barnum, S., Werner, A. P., Flach, B., O'Connell, S., Bock, K. W., Minai, M., Nagata, B. M., Andersen, H. et al. (2020). Evaluation of the mRNA-1273 vaccine against SARS-CoV-2 in nonhuman primates. The New England Journal of Medicine. https://doi.org/10.1056/ NEJMoa2024671.

Cortegiani, A., Ippolito, M., Ingoglia, G., \& Einav, S. (2020a). Chloroquine for COVID-19: Rationale, facts, hopes. Journal of Critical Care. https://doi.org/10.1186/ s13054-020-02932-4.

Cortegiani, A., Ingoglia, G., Ippolito, M., Giarratano, A., \& Einav, S. (2020b). A systematic review on the efficacy and safety of chloroquine for the treatment of COVID-19. Journal of Critical Care, 53, 279-283.

Coutard, B., Valle, C., de Lamballerie, X., Canard, B., \& Seidah, N. G. (2020). The spike glycoprotein of the new coronavirus 2019-nCoV contains a furin-like cleavage site absent in $\mathrm{CoV}$ of the same clade. Antiviral Research, 176, 104742.

Das, P., Majumder, R., Mandal, M., \& Basak, P. (2020). In-Silico approach for identification of effective and stable inhibitors for COVID-19 main protease ( $\mathrm{M}^{\text {pro }}$ ) from flavonoid based phytochemical constituents of Calendula officinalis. Journal of Biomolecular Structure and Dynamics. https://doi.org/10.1080/07391102.2020.17 96799.

Deng, L., Li, C., Zeng, Q., Liu, X., Li, X., Zhang, H., Hong, Z., \& Xia, J. (2020). Arbidol combined with $\mathrm{LPV} / \mathrm{r}$ versus $\mathrm{LPV} / \mathrm{r}$ alone against corona virus disease 2019: A Retrospective Cohort Study. The Journal 
of Infection. https://doi.org/10.1016/j. jinf.2020.03.002

Dong, L., Hu, S., \& Gao, J. (2020). Discovering drugs to treat coronavirus disease 2019 (COVID-19). Drug Discovery \& Therapeutics, 14, 58-60.

Dorward, J. \& Gbinigie, K. (2020). Lopinavir/ ritonavir: A rapid review of effectiveness in COVID-19. Centre for Evidence-Based Medicine: University of Oxford.

Duan, K., Liu, B., Li, C., Zhang, H., Yu, T., Qu, J., Zhou, M., Chen, L., Meng, S., Hu, Y. et al. (2020). Effectiveness of convalescent plasma therapy in severe COVID-19 patients [published online ahead of print, 2020 Apr 6]. Proceedings of the National Academy of Sciences of the United States of America. https://doi.org/10.1073/ pnas. 2004168117.

EA, J. A., \& Jones, I. M. (2019). Membrane binding proteins of coronaviruses. Future Virology, 14(4), 275-286.

El-Aziz, T. M. A., \& Stockand, J. D. (2020). Recent progress and challenges in drug development against COVID-19 coronavirus (SARS-CoV-2)-an update on the status. Infection, Genetics and Evolution. https://doi.org/10.1016/j.meegid. 2020.104327.

Eynde, J. J. V. (2020a). COVID-19: An update about the discovery clinical trial. Pharmaceuticals. https://doi.org/10.3390/ ph13050098.

Eynde, J. J. V. (2020b). COVID-19: A brief overview of the discovery clinical trial. Pharmaceuticals. https://doi.org/10.3390/ ph13040065.

Fan, H.-H. Wang, L.-Q., Liu, W.-L., An, X.-P., Liu, Z.-D., He, X.-Q., Song, L.-H., \& Tong, Y.-G. (2020a). Repurposing of clinically approved drugs for treatment of coronavirus disease 2019 in a 2019-novel coronavirus (2019-nCoV) related coronavirus model. Chinese Medical Journal, 133(9), 10511056.
Fan, Q., \& Zhang, B. (2020b). Safety profile of the antiviral drug Remdesivir: An update. Biomedicine \& Pharmacology. https://doi. org/10.1016/j.biopha.2020.110532.

Fedson, D. S., Opal, S. M., \& Rordam, O. M. (2020). Hiding in plain sight: An approach to treating patients with severe COVID-19 infection. American Society for Microbiology. https://doi.org/10.1128/ mBio.00398-20.

Folegatti, P. M., Ewer, K. J., Aley, P. K., Angus, B., Becker, S., Belij-Rammerstorfer, S., et al. (2020). Safety and immunogenicity of the ChAdOx1 nOCV-19 vaccine against SARS-CoV-2: A preliminary report of a phase 1/2, single-blind, randomised controlled trial. The Lancet, 396(10249), 467-478.

Frellick, M. (2020). No Hydroxychloroquine benefit in small, randomized COVID-19 trial. Medscape.

Frick, D. N., \& Lam, A. M. (2006). Understanding helicases as a means of virus control. Current Pharmaceutical Design, 12(11), 1315-1338.

Gao, Q., Tian, Z., \& Yang, X. (2020a). Breakthrough: Chloroquine phosphate has shown apparent efficacy in treatment of COVID-19 associated pneumonia in clinical studies. BioScience Trends, 14, 7273.

Gao, Q., Bao, L., Mao, H., Wang, L., Xu, K., Yang, M., Li, Y., Zhu, L., Wang, N., Lv, Z., et al. (2020b). Development of an inactivated vaccine candidate for SARSCoV-2. Science. https://doi.org/10.1126/ science.abc1932.

Gautret, P., Lagier, J-C., Parola, P., Hoang, V. T., Meddeb, L., Mailhe, M., Doudier, B., Courjon, J., Giordanengo, V., Vieira, V. E. et al. (2020). Hydroxychloroquine and azithromycin as a treatment of COVID-19: Results of an open-label non-randomized clinical trial. International Journal 
of Antimicrobial Agents. https://doi. org/10.1016/j.ijantimicag.2020.105949.

Geoghegan, S., O’Callaghan, K. P., \& Offit, P. A. (2020). Vaccine safety: Myths and misinformation. Frontiers in Microbiology. https://doi.org/10.3389/fmicb.2020.00372.

Ghosh, R., Chakraborty, A., Biswas, A., \& Chowdhuri, S. (2020). Identification of polyphenols from Broussonetia papyrifera as SARS-CoV-2 main protease inhibitors using in silico docking and molecular dynamics simulation approaches. Journal of Biomolecular Structure and Dynamics. https://doi.org/10.1080/07391102.2020.18 02347.

Gildenhuys, S. (2020). Expanding our understanding of the role polyprotein conformation plays in the coronavirus life cycle. Biochemical Journal. https://doi. org/10.1042/BCJ20200223.

Goncalves, A., Bertrand, J., Ke, R., Comets, E., Lamballerie, X., Malvy, D., Pizzorno, A., Terrier, O., Calatrava, M. R., Mentre, F., Smith, P., Perelson, A. S., \& Guedj, J. (2020). Timing of antiviral treatment initiation is critical to reduce SARS-CoV-2 viral load. Pharmacometrics and Systems Pharmacology. https://doi.org/10.1002/psp4.12543.

Gordon, C. J., Tchesnokov, E. P., Woolner, E., Perry, J. K., Feng, J. Y., Porter, D. P., \& Gotte, M. (2020). Remdesivir is a direct-acting antiviral that inhibits RNA-dependent RNA polymerase from severe acute respiratory syndrome coronavirus 2 with high potency. Journal of Biological Chemistry, 295(20), 6785-6797.

Harrison, C. (2020). Coronavirus puts drug repurposing on the fast track. Nature Biotechnology, 38, 379-381.

Hilgenfeld, R. (2014). From SARS to MERS: Crystallographic studies on coronaviral proteases enable antiviral drug design. FEBS Journal, 281(18), 4085-4096.

Hoffmann, M., Kleine-Weber, H., Schroeder, S., Krüger, N., Herrler, T., Erichsen, S.,
Schiergens, T. S., Herrler, G., Wu, N-H., Nitsche, A., Muller, M. A., Drosten, C., \& Pohlmann, S. (2020). SARS-CoV-2 cell entry depends on ACE2 and TMPRSS2 and is blocked by a protease inhibitor. Cell, 181, 271-280.

Holshue, M. L., DeBolt, C., Lindquist, S., Lofy, K. H., Wiesman, J., Bruce, H., Spitters, C., Ericson, K., Wilkerson, S., Tural, A., Diaz, G., et al. (2020). First case of 2019 novel Coronavirus in the United States. The New England Journal of Medicine, 382, 929936.

Huaiyu, T. (2020). 2019-nCoV: New challenges from Coronaviruses. Chinese Journal of PreventiveMedicine.https://doi.org/10.3760 / cma.j.issn.0253-9624.2020.000.

Inovio Pahrmaceuticals. (2020). Inovio announced positive interim phase 1 data for INO-4800 vaccine for COVID-19. News Release.

Jackson, L. A., Anderson, E. J., Rouphael, N. G., Roberts, P. C., Makhene, M., Coler, R. N., McCullough, M. P., Chappell, J. D., Denison, M. R., Stevens, L. J., Pruijssers, A. J., McDermott, A. et al. (2020). An mRNA vaccine against SARS-CoV-2. The New England Journal of Medicine. https:// doi.org/10.1056/NEJMoa2022483.

Jean, S-S., Lee, P-I., \& Hsueh, P-R. (2020). Treatment options for COVID-19: The realityand challenges. Journal of Microbiology, Immunology and Infection. https://doi.org/10.1016/j.jmii.2020.03.034.

Jeong, G. U., Song, H., Yoon, G. Y., Kim, D., \& Kwon, Y-C. (2020). Therapeutic strategies against COVID-19 and structural characterization of SARS-CoV-2: A review. Frontiers in Microbiology. https://doi. org/10.3389/fmicb.2020.01723.

Jianxing, X. (2020). SARS-CoV-2 an unknown agent and challenges in vaccine development. Journal of Bio-X Research, 3(1), 3-5. 
Kaufmann, S. McElrath, M. J., Lewis, D. J. M., \& Giudice, G. D. (2014). Challenges and responses in human vaccine development. Current Opinion in Immunology, 28, 18-26.

Khan, F. H. (2009). The elements of immunology. Vaccines. Chapter 16, pp 343-359.

Khan, K. H. (2013). DNA vaccines: Roles against diseases. Germs, 3(1), 26-35.

Kuo, L., Hurst, K. R., \& Masters, P. S. (2007). Exceptional flexibility in the sequence requirements for coronavirus small envelope protein function. Journal of Virology. 81(5), 2249-2262.

Lane, J. C. E., Weaver, J., Kostka, K., DuarteSalles, T., Abrahao, M. T. F., Alghoul, H., Alser, O., Thamir, A. M., Biedermann, P., Burn, E., et al. (2020). Safety of hydroxychloroquine, alone and in combination with azithromycin, in light of rapid widespread use for COVID-19: A multinational, network cohort and self-controlled case series study. Medrxiv Preprints. https://doi.org/10. 1101/2020.04.08.20054551.

Le, T. T., Andreaadakis, Z., Kumar, A., Roman, R. G., Tollefsen, S., Saville, M., \& Mayhew, S. (2020). The COVID-19 vaccine development landscape. Nature Reviews.

Ledford, H. (2020). Dozens of coronavirus drugs are in development - What happens next? Nature, 581, 247-248.

Lim, J., Jeon, S., Shin, H.-Y., Kim, M. J., Seong, Y. M., Lee, W. J., Choe, K.-W., Kang, Y. M., Lee, B., \& Park, S.-J. (2020). Case of the index patient who caused tertiary transmission of coronavirus disease 2019 in Korea: The application of lopinavir/ ritonavir for the treatment of COVID-19 pneumonia monitored by quantitative RTPCR. Journal of Korean Medical Science. https://doi.org/10.3346/jkms.2020.35.e79.

Liu, M., Wang, T., Zhou, Y., Zhao, Y., \& Zhang, Y. (2020). Potential role of ACE2 in coronavirus disease 2019 (COVID-19) prevention and management. Journal of Translational Internal Medicine, 8(1), 9-19.
Liu, R., \& Munroe, T. Exclusive: 90\% of China's Sinovac employees, families took coronavirus vaccine, says CEO. Reuters.

LiveScience. (2020a). Treatments for COVID-19: Drugs being tested against the coronavirus. News.

LiveScience. (2020b). Here are the most promising coronavirus vaccine candidates out there. News.

Lord, J. M. (2013). The effect of ageing of the immune system on vaccination responses. Human Vaccines and Immunotherapeutics, 9, 1364-1367.

Mitja, O., \& Clotet, B. (2020). Use of antiviral drugs to reduce COVID-19 transmission. Lancet Global Health. https://doi. org/10.1016/ S2214-109X(20)30114-5.

Mackenzie, J. S., \& Smith, D. W. (2020). COVID-19: A novel zoonotic disease caused by a coronavirus from China: What we know and what we don't. Microbiology Australia. https://doi.org/10.1071/MA200 13.

Martinez, M. A. (2020). Compounds with therapeutic potential against novel respiratory 2019 coronavirus. Antimicrobial Agents and Chemotherapy. https://doi. org/10.1128/AAC.00399-20.

McBride, R., van Zyl, M., \& Fielding, B. C. (2014). The coronavirus nucleocapsid is a multifunctional protein. Viruses, 6(8), 2991-3018.

Neuman, B. W., Kiss, G., Kunding, A. H., Bhella, D., \& Baksh, M. F. (2011). A structural analysis of $\mathrm{M}$ protein in coronavirus assembly and morphology. Journal of Structural Biology, 174(1), 11-22.

New Straits Times. (2020a). Malaysia to conduct clinical trials on potential Covid-19 medications. Nation.

New Straits Times. (2020b). Covid-19 drug Remdesivir fails in human trial. World. 
Nick, C., Heelan, B., \& Krishnamurthy, N. (2020). COVID-19 vaccine developmentPart 1: Progress and challenges. Parexel.

Oyston, P., \& Robinson, K. (2020). The current challenges for vaccine development. Journal of Medical Microbiology. https:// doi.org/10.1099/jmm.0.039180-0.

Pardi, N., Hogan, M. J., Porter, F. W., \& Weissman, D. (2018). mRNA vaccines A new era in vaccinology. Nature Reviews Drug Discovery, 17, 261-279.

Possas, C., Antunes, A. M. S., Magalhaes, J. L., Mendes, F. M. L., Ramos, M. P., Morais, J. D. S., \& Homma, A. (2020). Vaccines: Biotechnology market, coverage, and regulatory challenges for achieving sustainable development goals. In Keswani, C. (Ed.), Bioeconomy for sustainable development. Singapore: Springer.

Richardson, P., Griffin, I., Tucker, C., Smith, D., Oechsle, O., Phelan, A., \& Stebbing, J. (2020). Baricitinib as potential treatment for 2019-nCoV acute respiratory disease. The Lancet, 395, e30-e31.

Richman, D. D., \& Nathanson, N. Chapter 20-Antiviral Therapy. Viral Pathogenesis. http://dx.doi.org/10.1016/B978-0-12800964-2.00020-3.

Riou, J., \& Althaus, C. L. (2020). Pattern of early human-to-human transmission of Wuhan 2019 novel coronavirus (2019nCoV), December 2019 to January 2020. Eurosurveillance, 25(4), 2000058.

Robert Guroff, M. (2007). Replicating and non-replicating viral vectors for vaccine development. Current Opinion in Biotechnology, 18(6), 546-556.

Ryu, W. S. (2020). Chapter 26-Antiviral Therapy. Molecular Virology of Human Pathogenic Viruses, 367-381.

Saif, L. J. (2020). Vaccines for COVID-19: Perspectives, prospects, and challenges based on candidate SARS, MERS, and animal Coronavirus vaccines. European
Medical Journal. https://doi.org/10.33590/ $\mathrm{emj} / 200324$.

Sanders, J. M., Monogue, M. L., Jodlowski, T. Z., \& Cutrell, J. B. (2020). Pharmacologic treatments for coronavirus disease 2019 (COVID-19): A review. Journal of the American Medical Association. https://doi. org/10.1001/jama.2020.6019.

Sasaki, S., Takeshita, F., Xin, K-Q., Ishii, N., \& Okuda, K. (2003). Adjuvant formulations and delivery systems for DNA vaccines. Methods, 31(3), 243-254.

Satarker, S., \& Nampoothiri, M. (2020). Structural proteins in severe acuterespiratory syndrome coronavirus-2. Archieves of Medical Research. https://doi.org/ 10.1016/j.arcmed.2020.05.012.

Schmidt, C. (2020). Genetic Engineering could make a COVID-19 vaccine in months rather than years. Scientific American, 322(6), 4043.

Schoeman, D., \& Fielding, B. C. (2019). Coronavirus envelope protein: Current knowledge. Virology Journal, 16(1), 69.

Senger, M. R., Evangelista, T. C. S., Dantas, R. F., Santana, M. V. S., Goncalves, L. C. S., Neto, L. R. S., Ferreira, S. B., \& Silva-Junior, F. P. (2020). COVID-19: Molecular targets, drug repurposing and new avenues for drug discovery. Memorias do Instituto Oswaldo Cruz. https://doi. org/10.1590/0074-02760200254.

Sharma, J., Bhardwaj, V. K., Das, P., \& Purohit, R. (2020). Identification of naturally originated molecules as $\gamma$-aminobutyric acid receptor antagonist. Journal of Biomolecular Structure and Dynamics. https://doi.org/10.1080/07391102.2020.17 20818

Sharun, K., Dhama, K., Patel, S. K., Pathak, M., Tiwari, R., Singh, B. R., Sah, R., BonillaAldana, D. K., Rodriguez-Morales, A. J., \& Leblebicioglu, H. (2020). Ivermectin, a new candidate therapeutic against SARSCoV-2/COVID-19. Annals of Clinical 
Microbiology and Antimicrobials. https:// doi.org/10.1186/s12941-020-00368-w.

Sheahan, T. P., Sims, A. C., Leist, S. R., Sch€afer, A., Won, J., Brown, A. J., Montgomery, S. A., Hogg, A., Babusis, D., Clarke, M.O., Spahn, J. E., Bauer, L., Sellers, S., Porter, D., Feng, J.Y., Cihlar, T., Jordan, R., Denison, M. R., \& Baric, R. S. (2020). Comparative therapeutic efficacy of remdesivir and combination lopinavir, ritonavir, and interferon beta against MERS-CoV. Nature Communications, 11(1), 222.

Shen, C., Wang, Z., Zhao, F., Yang, Y., Li, J., Yuan, J., Wang, F., Li, D., Yang, M., Li, X. et al. (2020). Treatment of 5 critically ill patients with COVID-19 with convalescent plasma. JAMA Network.

Singh, S., Sk, M.F., Sonawane, A., Kar, P., \& Sadhukhan, S. (2020). Plant-derived natural polyphenols as potential antiviral drugs against SARS-CoV-2 via RNA-dependent RNA polymerase (RdRp) inhibition: an insilico analysis. Journal of Biomolecular Structure and Dynamics. https://doi.org/10 .1080/07391102.2020.1796810.

Smith, P. F., Dodds, M., Bentley, D., Yeo, K., \& Rayner, C. (2020). Dosing will be a key success factor in repurposing antivirals for COVID-19. British Journal of Clinical Pharmacology. https://doi.org/10.1111/bcp. 14314.

Subissi, L., Posthuma, C. C., Collet, A., Zevenhoven-Dobbe, J. C., Gorbalenya, A. E., Decroly, E., Snijder, E. J., Canard, B., \& Imbert, I. (2014). One severe acute respiratory syndrome coronavirus protein complex integrates processive RNA polymerase and exonuclease activities. Proceedings of the National Academy of Sciences of the United States of America, 111(37), E3900-E3909.

Taccone, F. S., Gorham, J., \& Vincent, J-L. (2020). Hydroxychloroquine in the management of critically ill patients with COVID-19: the need for an evidence base.
The Lancet Respiratory Medicine. https:// doi.org/10.1016/S2213-2600(20)30172-7.

Tang, W., Cao, Z., Han, M., Wang, Z., Chen, J., Sun, W., Wu, Y., Xiao, W., Liu, S., Chen, E., et al. (2020). Hydroxychloroquine in patients mainly with mild to moderate COVID-19: An open-label, randomized, controlled trial. Medrxiv Preprints. https://doi.org/10.1101/ 2020.04.10.20060558.

The National Academics. (2020). Vaccines and medicines. Infectious Diseases.

Tobaiqy, M., Qashqary, M., Al-Dahery, S., Mujallad, A., Hershan, A. A., Kamal, M. A., \& Helmi, N. (2020). Therapeutic management of patients with COVID-19: A systematic review. Infection Prevention in Practice. https://doi.org/10.1016/j. infpip.2020.100061.

Unhale, S. S., Bilal, Q., Sanap, S., \& Thakhre, S. (2020). A review on corona virus (COVID-19). International Journal of Pharmaceuticals and Life Sciences, 6(4), 109-115.

UNICEF. (2020). Vaccinations and COVID-19: What parents need to know. UNICEF Publications. University of Oxford. Oxford COVID-19 vaccine begins human trial stage. News and Events. United Kingdom.

U.S Department of Health and Human Services. (2020). Vaccine Types. Vaccines.gov.

U.S National Library of Medicine. (2020a). Interventional Studies. ClinicalTrials.gov.

U.S National Library of Medicine. (2020b). An investigation into beneficial effects of Interferon Beta 1 $\alpha$, compared to Interferon beta-1 $\beta$, and the base therapeutic regiment in moderate to severe COVID-19: a randomized clinical trial (COVIFERON). ClinicalTrials.gov.

Uzunova, K., Filipova, E., Pavlova, V., \& Vekov, T. (2020). Insights into antiviral mechanisms of remdesivir, lopinavir/ritonavir and chloroquine/hydroxychloroquine affecting the new SARS-CoV-2. Biomedicine \& 
Pharmacotherapy. https://doi.org/10.1016/ j.biopha.2020.110668.

Venkatagopalan, P., Daskalova, S. M., Lopez, L. A., Dolezal, K. A., \& Hogue, B. G. (2015). Coronavirus envelope (E) protein remains at the site of assembly. Virology, 478, 7585 .

Vincent, M. J., Bergeron, E., Benjennet, S., Erickson, B. R., Rollin, P. E, Ksiazek, T. G., Seidah, N. G., \& Nichol, S. T. (2005). Chloroquine is a potent inhibitor of SARS coronavirus infection and spread. Journal. https://doi.org/10.1186/1743-422X-2-69.

Wang, M., Cao, R., Zhang, L., Yang, X., Liu, J., Xu, M., et al. (2020a). Remdesivir and chloroquine effectively inhibits the recently emerged novel coronavirus (2019-nCoV) in vitro. Cell Research, 30, 269-271.

Wang, M., Cao, R., Zhang, L., Yang, X., Liu, J., Xu, M., Shi, Z., Hu, Z., Zhong, W., \& Xiao, G. (2020b). Remdesivir and chloroquine effectively inhibit the recently emerged novel coronavirus (2019-nCoV) in vitro. Cell Research, 30, 269-271.

Walls, A. C., Park, Y. J., Tortorici, M. A., \& McGuire, A. T. (2020). Structure, function and antigenicity of the SARS-CoV-2 spike glycoprotein. Cell, 181(2), 281-292.

Wei, C. J., Crank, M. C., Shiver, J., Graham, B. S., Mascola, J. R., \& Nabel, G. J. (2020). Next-generation influenza vaccines: opportunities and challenges. Nature Reviews Drug Discovery, 19, 239-252.

Weller, I. V. D., \& Williams, I. G. (2001). ABC of AIDS antiretroviral drugs. 322, 14101412. BMJ Publishing Group Ltd.

Wondmkun, Y. T., \& Mohammed, O. A. (2020). A review on novel drug targets and future directions for COVID-19 treatment. Dovepress, 14, 77-82.

World Bank. (2020). Projects: Global overview. COVID-19 Responses. Washington.

World Health Organization. (2020a). WHO Coronavirus Disease (COVID-19) Dashboard. WHO.
World Health Organization. (2020b). "Solidarity" clinical trial for COVID-19 treatments. Global research on coronavirus disease (COVID-19).

World Health Organization. (2020c). Malaysia starts global "Solidarity Trial"-A research effort to test possible treatments for COVID-19. News.

World Health Organization. (2020d). Landscape analysis of therapeutics as 21st March 2020. R \& D Blueprint.

Yan, D., Liu, X., Zhu, Y., Huang, L., Dan, B., Zhang, G., \& Gao, Y. (2020). Factors associated with prolonged viral shedding and impact of Lopinavir/Ritonavir treatment in patients with SARS-CoV-2 infection. medRxiv. https://doi.org/10.1101 /2020.03.22.20040832.

Yang, X., Yu, Y., Xu, J., Shu, H., Xia, J., Liu, H., Wu, Y., Zhang, L., Yu, Z., Fang, M., et al. (2020). Clinical course and outcomes of critically ill patients with SARS-CoV-2 pneumonia in Wuhan, China: A singlecentered, retrospective, observational study. The Lancet Respiratory Medicine, 8, 475481.

Yao, X., Ye, F., Zhang, M., Cui, C., Huang, B., Niu, P., Liu, X., Zhao, L., Dong, E., Song, C., Zhan, S., Lu, R., Li, H., Tan, W., \& Liu, D. (2020). In vitro antiviral activity and projection of optimized dosing design of hydroxychloroquine for the treatment of severe acute respiratory syndrome coronavirus 2 (SARS-CoV-2). Clinical Infectious Diseases, 71(15), 732-739.

Ye, M., Fu, D., Ren, Y., Wang, F., Wang, D., Zhang, F., Xia, X., \& Lv, T. (2020). Treatment with convalescent plasma for COVID-19 patients in Wuhan, China. Journal of Medical Virology. https://doi. org/10.1002/jmv.25882.

Yoshimoto, F. K. (2020). The proteins of severe acute respiratory syndrome Coronavirus-2 (SARS CoV-2 or n-COV19), the cause of Covid-19. The Protein Journal, 39, 198216. 
Zeng, Y., Ye, L., Zhu, S., Zheng, H., \& Zhao, P. (2008). The nucleocapsid protein of SARS-associated coronavirus inhibits B23 phosphorylation. Biochemical and Biophysical Research Communications, 369(2), 287-291.

Zhang, L., Lin, D., Sun, X., Curth, U., Drosten, C., Sauerhering, L., Becker, S., Rox, K., \& Hilgenfeld, R. (2020). Crystal structure of SARS-CoV-2 main protease provides a basis for design of improved alpha- ketoamide inhibitors. Science, 368, 409412.

Zhu, F. C., Guan, X. H., Li, Y. H., Huang, J. Y., Jiang, T., Hou, L. H., et al. (2020). Immunogenicity and safety of a recombinant adenovirus type-5-vectored COVID-19 vaccine in healthy adults aged 18 years or older: a randomized, doubleblind, placebo-controlled, phase 2 trial. The Lancet, 396(10246), 479-488. 